\title{
PROFIL BERPIKIR REFLEKTIF SISWA BERGAYA KOGNITIF VISUALIZER DENGAN KEMAMPUAN MATEMATIKA TINGGI DALAM MENYELESAIKAN SOAL HOTS
}

\author{
Soffil Widadah \\ STKIP PGRI SIDOARJO \\ soffdah16@gmail.com
}

\begin{abstract}
Abstrak
Kegagalan siswa dalam menyelesaikan soal HOTS secara garis besar bisa disebabkan oleh tidak bertindaknya siswa sesuai dengan pengalaman pribadi, tidak menganalisis dan mengaklasifikasi pengetahuan untuk mengevaluasi tindakan, serta tidak merenungkan atau memikirkan kembali apa yang telah dilakukan untuk mengambil kesimpulan. Hal tersebut merupakan fase berpikir reflektif, di mana berpikir reflektif merupakan proses mengumpulkan informasi dan berpikir logis untuk membuat keputusan dan mengevaluasi keputusan yang telah diambil. Penelitian ini bertujuan untuk mendeskripsikan profil berpikir reflektif siswa bergaya kognitif Visualizaer berkemampuan matematika tinggi dalam menyelesaikan soal HOTS. Penelitian yang dilakukan secara eksploartif ini mengahasilkan data bahwa subjek tidak bisa menyelesaikan soal dengan berbagai cara, artinya subjek tidak memenuhi satu indikator dari lima indikator berpikir reflektif. Dengan demikian dapat dikatakan pada fase berpikir reflektif subjek belum menganalisis dan mengklasifikasi pengetahuan untuk mengevaluasi tindakan.
\end{abstract}

\section{Kata Kunci: Berpikir Reflektif, Visualizer, Kemampuan Matematika Tinggi, HOTS}

\begin{abstract}
Students' failures in solving HOTS questions in general can be caused by students' inaction according to personal experience, not analyzing and classifying knowledge to evaluate actions, and not reflecting or rethinking what has been done to draw conclusions. This is a reflective thinking phase, where reflective thinking is a process of gathering information and thinking logically to make decisions and evaluate the decisions that have been taken. This study aims to describe the reflective thinking profile of Visualizaer students with high mathematical abilities in solving HOTS questions. This exploratory research produced data that the subject could not solve the problem in various ways, meaning that the subject did not meet one indicator of the five indicators of reflective thinking. Thus it can be said that in the reflective thinking phase the subject has not analyzed and classified knowledge to evaluate actions.
\end{abstract}

Keywords: Reflective Thinking, Visualizer, High Mathematical Ability, HOTS 


\section{PENDAHULUAN}

Menyelesaikan soal kategori HOTS (Higher Order Thinking Skills) tidak hanya memerlukan keratifitas, berpikir kritis, dan berpikir logis saja tetapi juga memerlukan berpikir reflektif. Untuk menyelesaikan soal HOTS terkadang siswa harus memanggil kembali skema yang sudah lama karena siswa diharapkan mencapai fase mencipta dan mengkreasi. Susanti, Kusumah, dan Sabandar, 2014). Hal tersebut dilakukan untuk membuat keputusan dalam menyelesaikan soal yang memang membutuhkan berpikir tingkat tinggi. Proses membuat keputusan yang masuk akal dan logis mengenai masalah kehidupan sehari-hari dan menilai konsekuensi dari keputusan ini. Hal ini berarti bahwa seseorang yang membuat sesuatu yang masuk akal dan logis dalam memutuskan keputusan tersebut serta menilai konsekuensi dari keputusan yang telah dibuat disebut berpikir reflektif. Penjelasan tentang berpikir reflektif juga dijelaskan oleh Taggart \& Wilson (2005) "Reflective thinking is the process of making informed and logical decisions on educational matters and the assessing the consequences of these decisions"

Setiap individu pasti pernah berpikir reflektif karena berpikir reflektif merupakan pengintegrasian aktivitas masa lalu seseorang dengan apa yang sedang dilakukan pada saat ini untuk meningkatkan kinerja pada masa depan. Dalam pembelajaran, berpikir reflektif bukan hanya aktivitas yang dilakukan siswa pada akhir pertemuan, tetapi refleksi juga bisa dilakukan setelah satu materi selesai. Berpikir reflektif dilakukan secara sadar dan aktif, terfokus dan terstruktur. Hal ini berarti bahwa dengan berpikir reflektif, siswa diharapkan bisa fokus dan terstruktur dalam berpikir dengan cara mengintegrasikan pengetahuan masa lalu dengan pengetahuan masa sekarang agar dapat meningkatkan pemahaman.

Ketika berpikir reflektif, individu harus berpikir secara aktif, kontinu, melakukan pertimbangan dengan cermat terhadap alasan yang dikemukakan dan dipercaya akan kebenarannya. Berpikir reflektif mempunyai tiga bagian penting (Dewey, 1933), yaitu keingintahuan terhadap fenomena yang dihadapi; merancang saran dan sarannya harus beraneka ragam; dalam mengambil kesimpulan menganut azas keteraturan. Siswa dikatakan berpikir reflektif, jika siswa tersebut: 1) merasa tidak bisa atau merasa kesulitan ketika menyelesaikan soal dan mengerucutkan permasalahan yang dihadapi; 2) 
mengupayakan memecahkan masalah dengan mencermati masalah yang dihadapi; 3) bisa memberikan lebih dari satu kemungkinan pemecahan masalah; 4) menghimpun data untuk mengembangkan ide dalam memecahkan masalah; 5) mengevaluasi apa yang telah dilakukan dan mencoba kemungkinan pemecahan masalah dan mencoba cara lain apabila percobaan penyelesaian mengalami kegagalan. Hal ini sesuai dengan pernyataan Given (2002) yang menyatakan bahwa berpikir reflektif merupakan memikirkan proses berpikir individu itu sendiri, misalnya apabila individu tersebut mengalami kegagalan, maka individu tersebut akan terus mencari penyebab kegagalan tersebut dan berupaya memperbaiki kegagalannya.

Schunk (2001) menyatakan bahwa tiga fase berpikir reflektif: 1) Reacting yaitu bertindak sesuai dengan pengetahuan pribadi untuk menyelesaikan permasalahan yang dihadapi; 2) Comparing, yaitu menganalisis dan mengklarifikasi pengetahuan individu untuk melakukan evaluasi terhadap apa yang diyakini dengan membandingkan tindakan dan pengetahuan yang dimilikinya; 3) Contemplating, merenungkan atau memikirkan kembali apa yang telah dilakukan dengan melakukan penguraian, memberikan informasi, melakukan pertimbangan, dan menyusun kembali situasi yang dihadapi. Peran penting dari berpikir reflektif adalah sebagai sarana untuk mendorong pemikiran siswa dalam situasi pemecahan masalah, karena memberikan siswa kesempatan untuk belajar dan memikirkan strategi terbaik untuk mencapai tujuan pembelajaran (Gurol, 2011). Berpikir reflektif membantu mengintegrasikan kemampuan berpikir (Rudd and Shermis dalam Gurol, 2011). Dengan demikian, berpikir reflektif juga membantu dalam menyatukan atau menggabungkan kemampuan berpikir. Hal yang perlu dilakukan untuk menggabungkan kemampuan berpikir reflektif ini dalam pembelajaran matematika adalah siswa perlu diberikan soal-soal yang bersifat tidak rutin seperti soal-soal pemecahan masalah atau berbasis masalah.

Perilaku siswa dalam menghadapi situasi masalah dalam belajar dapat dijelaskan oleh gaya kognitif yang dimiliki. Mendelson (2004) menyatakan bahwa gaya kognitif yang berkenaan dengan rutinitas seseorang dalam memanfaatkan alat inderanya dibagi menjadi dua kategori, yaitu visualizer dan 
verbalizer. Gaya kognitif ini dikembangkan oleh Paivio (dalam Mendelson (2004) dengan dua bagian: sistem visual dan sistem verbal, di mana sistem visual memanfaatkan gambar sedangkan sistem verbal memanfaatkan bahasa dalam memproses dan menyimpan informasi.

Seseorang yang mempunyai gaya kognitif visualizer mengacu pada gambar, lebih memahami ilustrasi, dan menikmati permainan visual. (Jonassen dalam Mendelson, 2004). Lebih lanjut Jonassen menyatakan bahwa visualizer lebih bisa belajar dengan lebih baik jika mereka memperoleh informasi dalam wujud visual, contohnya dalam bentuk gambar, grafik, diagram, dan peta..

Dengan demikian dapat dikatakan bahwa seseorang yang mempunyai gaya kognitif visualizer lebih mudah untuk menerima, memproses, menyimpan dan menggunakan informasi dalam bentuk gambar.

\section{METODE}

Subjek dalam penelitian ini adalah siswa Sekolah Menengah Pertama yang bergaya kognitif Verbalizer berkemampuan matematika tinggi. Gaya kognitif subjek diketahui dari tes gaya kognitif, sedangkan untuk kemampuan matematika peneiti berkonsultasi dengan guru sekolah.

Data penelitian eksploratif yang menggunakan pendekatan kualitatif ini diperoleh dari hasil tulisan subjek dalam menyelesaikan soal HOTS, think aloud, dan introspection dari peneliti. Think aloud selama menyelesaikan soal yaitu subjek menyuarakan apa yang dipikirkan ketika mengerjakan soal, sedangkan dilakukan introspection apabila peneliti kurang jelas dengan apa yang dikatakan oleh subjek atau peneliti meminta penjelasan kepada subjek tentang apa yang dipikirkan (Someran, Bernard, sanberg, 1994). Selanjutnya, data yang diperoleh dianalisis dengan cara direduksi, disajikan dan diverikasi/pengambilan intisari dari sajian data.

\section{HASIL DAN PEMBAHASAN}

Analisis data dalam penelitian ini dilakukan berdasarkan indikator berpikir reflektif. Berikut profil berpikir reflektif siswa bergaya kognitif Visualizer berkemampuan matematika tinggi dalam menyelesaikan soal HOTS.

Indikator pertama, yaitu subjek merasa kesulitan ketika akan menyelesaikan soal dan mengerucutkan masalah tertuang 
dalam gambar, hasil think aloud, serta introspection berikut.

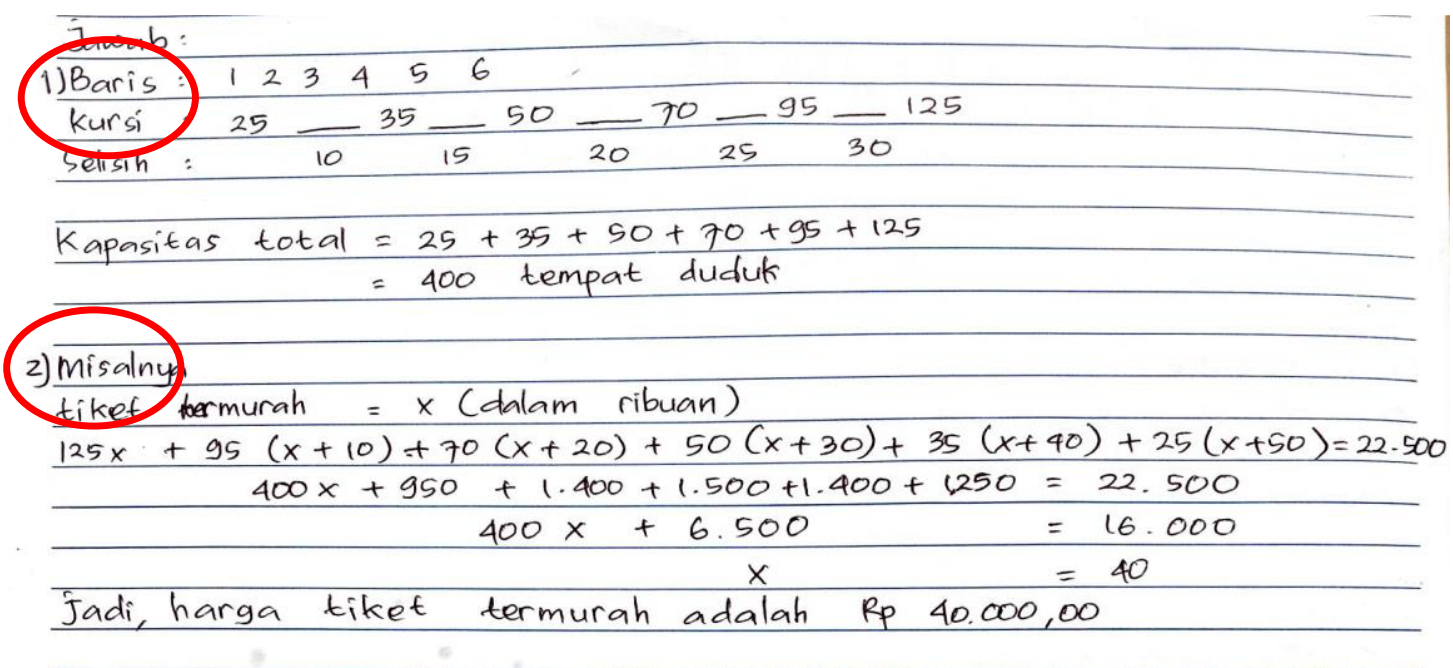

Gambar 1. Pekerjaan Subjek pada Indikator Pertama dan Kedua

Setelah membaca soal, subjek hanya terdiam seperti sedang berpikir, peneliti melakukan introspection.
$P$ : Apakah kamu merasa kesulitan dalam menyelesaikan soal yang ini?

$S:$ iya

$P$ : Apakah kamu masih ingin mengerjakan karena sulit? mengapa?

$S$ : Iya bu, karena saya penasaran

Berdasarkan hasil introspection terlihat bahwa subjek mempunyai rasa ingin tahu sehingga akan mengerjakan soal meskipun merasa akan mengalami kesulitan. Selanjutnya subjek mengerjakan dengan menuliskan nomor "1)" seperti terlihat pada gambar 1. sambil bergumam "pertama saya akan mencari barisan agar tahu jumlah kursi atau tempat duduk dalam gedung". Setelah diperoleh hasil, yaitu 400 tempat duduk subjek menuliskan nomor "2)" dan melanjutkan menjawab soal. Hal ini menunjukkan bahwa subjek mengerucutkan permasalahan untuk memperoleh hasil.

Indikator kedua, yaitu subjek mengupayakan memecahkan masalah dengan mencermati masalah yang dihadapi tertuang dalam gambar dalam Gambar 1., sedangkan hasil think aloud dan introspection sebagai berikut.

$P$ : Apakah kamu masih ingin mengerjakan karena sulit? mengapa?

$S:$ Iya bu, karena saya penasaran 
Hal ini menunjukkan bahwa subjek telah

Berdasarkan Gambar 1. dan berupaya mengerjakan soal.

introspection terlihat bahwa subjek Indikator ketiga, yaitu subjek bisa berusaha mememcahkan masalah atau memberikan lebih dari satu kemungkinan menyelesaikan soal. Begitu juga pemecahan masalah tertuang dalam berdasakan hasil think aloud subjek gambar, hasil think aloud, serta mengatakan "Pertama saya......" dan introspection berikut.

subjek mengerjakan soal sampai selesai.

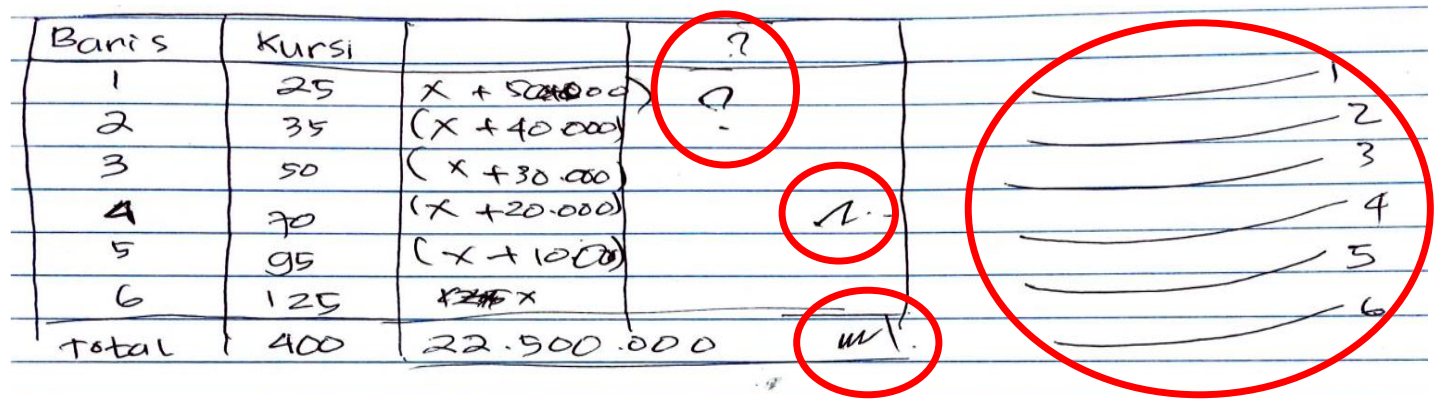

Gambar 2. Hasil Pekerjaan Siswa pada Indikator Ketiga

Setelah menyelesaikan soal, subjek tampak kembali membaca perintah/petunjuk soal, kemudian menuliskan sesuatu sambil bergumam "saya akan mencoba cara lain, yaitu dengan memasukkan data ke dalam tabel" Pada gambar 3. terlihat bahwa subjek mencoba mencari cara lain untuk menyelesaikan soal. Selain membuat tabel, subjek mencoba menggambar tempat duduk, tetapi kemudian subjek menuliskan "tanda tanya" dan sedikit mencoret-coret pada tabel sambil menggelengkan kepala dan berkata "sama saja dengan cara yang awal" selanjutnya subjek terdiam lama sampai akhirnya berkata "sudah bu, saya tidak bisa mencari cara lain"

Berdasarkan gambar dan hasil think aloud terlihat bahwa sudah berusaha untuk memberikan solusi lain tetapi mengalami kegagalan. Jika dilihat dari segi gaya kognitif, subjek mencoba membuat tabel dan menggambar urutan tempat duduk, hal ini sesuai dengan kriteri seseorang yang bergaya kognitif Visualizer, yaitu berorientasi pada gambar, lebih memahami ilustrasi, dan menikmati permainan visual (Jonassen dalam Mendelson, 2004). Sedangkan pada cara 
pertama, subjek tidak membuat tabel ataupun gambar kemungkinan hal ini disebabkan karena rentang nilai kriteria subjek tidak terlalu jauh dengan nilai kriteria gaya kognitif Visualizer.

Indikator keempat, yaitu subjek menghimpun data untuk mengembangkan ide dalam memecahkan masalah tertuang dalam gambar, hasil think aloud, serta introspection berikut.

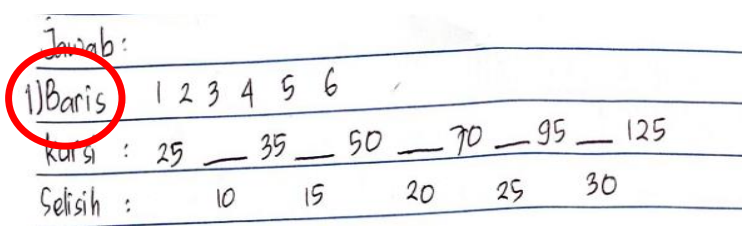

Gambar 3. Pekerjaan Subjek pada Indikator Keempat

Terlihat pada Gambar 3. subjek menghimpun data dengan menuliskan "1) baris: .........." sambil bergumam "pertama saya akan mencari barisan agar tahu jumlah kursi atau tempat duduk dalam gedung”. Selanjutnya peneliti melakukan introspection.

$P$ : Sebelum mengerjakan soal, apakah kamu mempunyai rencana, coba jelaskan rencanamu

$S$ : Iya, pertama saya akan mencari jumlah kursi, kemudian baru mencari harga tiket termurah berdasarkan yang diketahui dari soal
Dengan mengatakan "berdasarkan yang diketahui dari soal" menyiratkan bahwa subjek menghimpun data untuk mengembangkan ide dalam menyelesaikan soal. Selanjutnya peneliti melanjutkan introspection.

\section{$P$ : Apakah dalam merencanakan penyelesaian soal, kamu mengingat atau memnggil pengetahuanmu yang telah kamu pelajari. Jelaskan! \\ $S$ : Iya, saya teringat pola barisan dan soal-soal persamaan linier}

Begitu pula dengan mengatakan "saya teringat pola barisan dan soal-soal persamaan linier" menyiratkan bahwa subjek menghimpun data untuk mengembangkan ide dalam menyelesaikan soal. Hal ini selaras dengan pernyataan Sezer (dalam Chee 2012), berpikir reflektif merupakan kesadaran tentang apa yang diketahui dan apa yang diperlukan.

Indikator kelima, yaitu subjek mengevaluasi apa yang telah dilakukan dan mencoba kemungkinan pemecahan masalah dan mencoba cara lain apabila percobaan penyelesaian mengalami kegagalan serta membuat kesimpulan dideskripsikan sebagai berikut. 


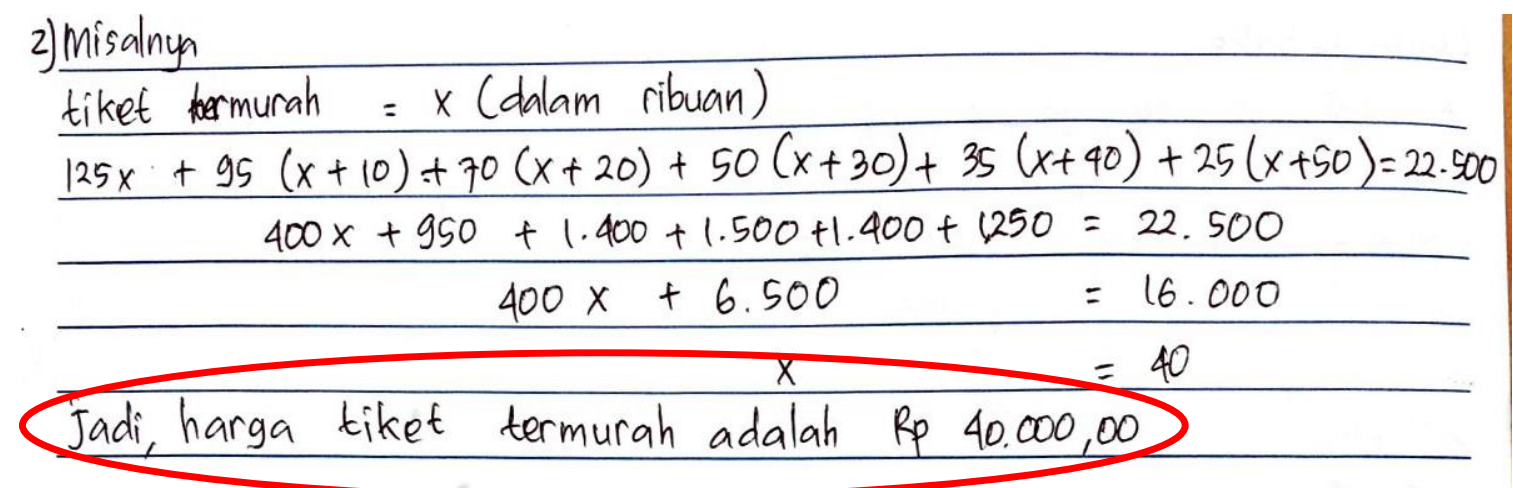

Gambar 4. Pekerjaan Subjek pada Indikator Kelima

Subjek mengatakan sudah melihat dengan mencermati masalah yang kembali jawaban yang telah diperoleh. dihadapi, tidak bisa memberikan lebih dari Hal ini sesuai dengan pendapat Rudd dan Shermis (Gurol, 2011) yang mengatakan bahwa berpikir reflektif dapat mendukung siswa menggabungkan kemampuan berpikirnya dengan melakukan evaluasi. Selain itu, terlihat pada Gambar 1. subjek sudah mencoba kemungkinan pemecahan masalah dan membuat kesimpulan dengan menuliskan "jadi harga tiket termurah adalah Rp. 400.000,00 (Gambar 4).

\section{SIMPULAN}

Berdasarkan hasil penelitian dan pembahasan yang telah disajikan dapat disimpulkan bahwa profil berpikir reflektif siswa bergaya kognitif dengan kemampuan matematika tinggi dalam menyelesaikan soal HOTS yaitu merasa kesulitan ketika menyelesaikan soal, satu kemungkinan pemecahan masalah, menghimpun data untuk mengembangkan ide dalam memecahkan masalah, mencoba kemungkinan pemecahan masalah dan menyimpulkan hasil yang diperoleh.

\section{DAFTAR PUSTAKA}

Cercone, K. (2008). Characteristic Of Edult Learner With Implicatios For Online Learning Design. online, AACE Journal, 16 (2), 137-159.

Chee., Pou. (2012). Reflective Thinking And Teaching Practices: A Precursor For Incorporating Critical Thinking Into The Classroom?. International Journal of Instruction. Vol 5. NO 1. (e-ISSN: 1308-1470). Diakses pada 24 Juli 2021 Pukul 12:21:26 WIB.

Dewey J. (1933). How We Think: A Restatement of the Relation of Reflective Thinking ti the Educative Process, Boston. MA: D.C., Heath and Company. 
Given, B. K. (2002). Teaching to the brain's natural learning systems. Washinton, DC: Association of Supervision and Curriculum Development.

Harel, Sowder. (2005). Advanced Mathematical - Thinking at any Age: Its Nature and Its Development. Mathematical Thinking and Learning volume 7(1): 27-50. Diakses pada 20 Desember 2017 Pukul 23:59 wib.

Gurol. A. (2011). Determining the reflective thinking skills of pre-service teachers in learning and teaching process. Energy Education Science and Technology Part B: Social and Educational Studies 2011 Volume (issue) 3(3): 387-402.

King, FJ., Goodson, Ludwika., Rohani., Faranak. (1993). Higher Order Thinking Skills, A publication of the Educational Services program, now known as the Center for Advancement of Learning and Assessment.

Lee, H. (2005). Understanding and assessing preservice teacher's reflective thinking. Teaching and Teacher Education. USA. 21 (699-715).

Mendelson, A. L., \& Thorson, E. (2004). How verbalizers and visualizers process the newspaper environment. Journal of Visual Literacy, 54(3), 474491.

Mendelson, A. L. 2004. "For Whom is a Picture Worth a Thousand Words? Effects of the Visualizing Cognitive. Phliadelpia: Journal of Literacy. Volume 24.

Schunk, D.H. (2001). Social cognitive theory and selfregulated learning. In B.J. Zimmerman \& D.H Schunk (Eds.), Self-regulated learning and academic achievement: Theoretical perspectives (2nd ed., pp. 125-152). Mahwah, NJ: Erlbaum.

Someren, M. W. V, Bernard, Y. F, Sanberg, J. A. C. (1994). The Think Aloud, A Practical Guide To Modelling Cognitif Processes. Departement of Social Science Informatics. University of Amsterdam. London: Academic Press.

Susanti, E., Kusumah, Y. S., \& Sabandar, J. (2014). Computer-Assisted Realistic Mathematics Education for Enhancing Students' Higher-Order Thinking Skills (Experimental Study in Junior High School in Palembang, Indonesia). Journal of Education and Practice, 5(18), 51-58.

Taggart, G. L., \& Wilson, A. P. (2005). Promoting reflective thinking in teachers: 50 action strategies (2nd ed.). American Psychological Association: Corwin Press.

Widdiharto, R. (2008). Diagnosis Kesulitan Belajar Matematika SMP dan Alternatif Proses Remidinya. Yogyakarta: Pusat Pengembangan dan Pemberdayaan Pendidik dan Tenaga Kependidikan Matematika. 
Widadah, Profil Berpikir Reflektif ... 